\title{
Research on Coordinated Development of a Railway Freight Collection and Distribution System Based on an "Entropy-TOPSIS Coupling Development Degree Model” Integrated with Machine Learning
}

\author{
Yun Jing, Si-Ye Guo $\mathbb{D}$, Xuan Wang $(\mathbb{D}$, and Fang-Qiu Chen $\mathbb{D}$ \\ School of Traffic and Transportation, Beijing Jiaotong University, Beijing 100044, China \\ Correspondence should be addressed to Si-Ye Guo; 18120799@bjtu.edu.cn
}

Received 4 June 2020; Revised 24 July 2020; Accepted 10 August 2020; Published 15 September 2020

Academic Editor: Naixue Xiong

Copyright $(92020$ Yun Jing et al. This is an open access article distributed under the Creative Commons Attribution License, which permits unrestricted use, distribution, and reproduction in any medium, provided the original work is properly cited.

\begin{abstract}
In recent years, with the gradual networking of high-speed railways in China, the existing railway transportation capacity has been released. In order to improve transportation capacity, railway freight transportation enterprises companies have gradually shifted the transportation of goods from dedicated freight lines to passenger-cargo lines. In terms of the organization form of collection and distribution, China has a complete research system for heavy-haul railway collection and distribution, but the research on the integration of collection and distribution of the ordinary-speed railway freight has not been completed. This paper combines the theories of the integration of collection and distribution theory, coordination theory, and coupling theory and incorporates the machine learning fuzzy mathematics to construct an "Entropy-TOPSIS Coupling Development Degree Model" for dynamic intelligent quantitative analysis of the synergy of railway freight collection and distribution systems. Finally, we take the Tongchuan Depot of "China Railway Xi'an Group Co., Ltd." as a research object to construct a target system and use the intelligent information acquisition system to collect basic data. The analysis results show that through the coordinated control of the freight collection and distribution system, the coordination between the subsystems of the integrated freight collection and distribution system is increased by $5.94 \%$, which verifies the feasibility of the model in the quantitative improvement of the integration of collection and distribution system. It provides a new method for the research of integrated development of railway freight collection and distribution.
\end{abstract}

\section{Introduction}

In recent years, China's high-speed railway construction has been developing very rapidly. By the end of 2019, the operating mileage of high-speed railways has exceeded 35,000 kilometers, leading to a widely-covered high-speed railway network between major cities. With the rapid advancement of the high-speed railway network, the existing railway transportation capacity has been released, which makes it possible for railway transportation enterprises to gradually expand the freight organization from the dedicated freight line to the passenger-cargo line to improve freight transportation capacity. With the rapid development of various modes of transportation, the transportation mode is moving towards the direction of collaboration, cooperation and the establishment of joint transportation system. To meet the needs of railway logistics and to improve railway freight volume and the transportation network's efficiency, it is of vital importance to integrate the freight collection and distribution based on railway transportation channels and accelerate the speed of cargo assembly and delivery. However, the traditional static traffic flow control is no longer suitable for the current dynamic changing collection and distribution system.On the other hand, the integrated transportation organization, as well as dynamic control and integration of the railway freight collection and distribution system, will both help to coordinate the overall 
integrated configuration, which plays a key role in the coordinated development of railway collection and distribution system, such as improving the planning and layout, coordinating the point and line capacity, and matching of technical standards.Simultaneously, the research is conducive to actively carrying out collaborative marketing, realizing dynamic coordination and distribution of empty and heavy cargoes, expending the transportation market share of transportation, and achieving the purpose of unblocked transportation and maximum benefits.

This paper provides a new method for the research of integrated development of railway freight collection and distribution system. Based on the theories of integration of collection and distribution theory, synergy theory, coupling theory, and fuzzy mathematics, we construct an "EntropyTOPSIS Coupling Development Degree Model" for dynamic and intelligent quantitative analysis of the degree of synergy between collection and distribution systems. Through the Entropy-TOPSIS model, we obtain the collaborative development evaluation index, which can help us make a longitudinal evaluation of the comprehensive coordination situation of the railway freight collection and distribution system. On this basis, we also construct the coupling development degree model to obtain the coupling development degree among the various subsystems, so that we can quantify the synergy between the collection and distribution integrated systems. The result provides a substantive reference basis for railway transportation companies to further strengthen the integrated regulation of freight collection and distribution system, which also plays an important role in the planning and construction of the railway collection and distribution system channel, the optimization of resource allocation, the improvement of transportation capacity and the diversified development of railway freight transportation.

The remainder of this study is organized as follows: Section 2 summarizes the related literature on the collection and distribution system.Section 3 clarifies the cooperative connotation of the integration of the railway freight collection and distribution system, and establishes an evaluation index system for the cooperative configuration of the railway freight collection and distribution system. Section 4 constructs a mathematical model, called the "EntropyTOPSIS Coupling Development Degree Model" for quantitatively analyzing the synergy of the railway freight collection and distribution system. Section 5 takes Tongchuan Depot, which is a sub-division of "China Railway Xi'an Group Co.,Ltd.", as a research object and carries out a quantitative analysis of the coordinated development of the target collection and distribution system, to verify the feasibility of the model. Finally, Section 6 offers conclusions and future research directions.

\section{Literature Review}

The concept of the collection and distribution system theory first appeared in international port cargo transportation. Having a suitable geographical location and an efficient collection and distribution network is a guarantee for the port healthy development. With the development of logistics transportation, a comprehensive collection and distribution system becomes an effective way to diversify the port. Article $[1,2]$ pointed out from the perspective of shipping links that the development of port collection and distribution system was mainly affected by the conditions of the collection and distribution infrastructure, the adaptability of the collection and distribution method, and the environment. Huang [3] constructed an optimization model of the Shanghai Port container transportation system for the port collection and distribution system and predicted the development bottleneck of the Shanghai Port container transportation collection and distribution system. Geng [4] put forward the basic characteristics of the medium and long-term development of the port collection and distribution railway and the problems that the current development needs to address, which provided theoretical support for promoting the development of combined transportation of railway and water, accelerated the construction of an integrated transportation system, and achieved cost reduction and efficiency increase in the logistics industry. Xu [5] analyzed the current situation and existing problems of the collection and distribution systemof Tonghai Port Area, and provided reference for the connection of the special line of the Shugang Railway and the station setting. The research of the heavy-haul railway collection and distribution system is also relatively complete. $\mathrm{Wu}[6]$ analyzed the main coordination factors of the railway transportation system in the Caofeidian port area from three aspects: facilities, production organization and operation management and used cloud model to evaluate the coordination of the railway transportation system. Kong and $\mathrm{He}$ [7] explored the capacity coordination of the Shenhua heavy-duty coal transportation special line collection and distribution system from the three subsystems. Besides, they established a capacity coordination model for the collection and distribution system of the heavy-haul coal transportation dedicated line, and proposed a classification scheme for the coordination degree to provide a reference for optimizing the heavy-haul railway collection and distribution system. Feng et al. [8] analyzed the connotation and synergy motivation of the integrated organization of the railway heavy-duty collection and distribution system and believed that it was determined by the self-organization, instability principle, dominating principle, and order parameter principle of the railway heavy-duty transportation system. From the system perspective, Yu [9] analyzed the heavy-haul railway collection and distribution system and proposed research methods. The results show that the method can not only effectively meet the transportation target effectively, but realize the expansion and transformation of the railway transportation subsystems as well. Therefore, it can meet future development needs.

As for the freight flow control, the allocation of empty and heavy cargoes is an important part of the railway freight collection and distribution link. Therefore, the realization of the dynamic control of the flow of cargoes will facilitate the alleviation of the operating pressure of busy stations and the improvement of the efficiency of integrated operations. Liang and Lin [10] constructed a strategic optimization 
model for the organization of dynamic train flow in railway transportation. The model combined heavy and empty cargo transportation and designed an improved genetic algorithm based on integer coding that can solve large-scale network problems. Regarding the bottleneck section of the railway network, Wang et al. [11] established a multiobjective planning model for the optimal allocation of transport capacity resources in the bottleneck section, and verified the rationality and effectiveness of the method for calculating traffic flow and the optimization of transport capacity resource allocation in the bottleneck section. Xue et al. [12] provided the calculation method of the coupling degree between the station stage plan and the dynamic traffic flow. The results of the calculation example showed that the proper traffic flow allocation can improve the coupling degree between the stage plan and the dynamic traffic flow to a certain extent.

In terms of the research theory, this paper mainly deals with collaborative marketing in synergy. Varadarajan [13] summarized the connotation and application scope of symbiotic marketing, studied the impact of business environment changes and organizational development on symbiotic marketing, and discussed the feasibility of symbiotic marketing and its planning and execution. Xie [14] started from the definition of collaborative marketing, analyzed the principles of selecting collaborative objects, and gave suggestions on how to choose collaborative objects for enterprises. As for the research methods, this paper mainly involves evaluation cooperative model and coordinated development model. Both are often used in the fields of economics and systems science. Sun [15] used fuzzy comprehensive evaluation and a method with preference to evaluate partners. Yin and Bao [16] used the Entropy-TOPSIS method to conduct financial risk evaluation research on high-tech enterprises. Wang and Tang [17], taking the Dongting Lake area as a research object, and based on the construction of an evaluation index system for the coordinated development of the Ecological-Economic-Society complex system, introduced the coupling coordination degree function was introduced to empirically measure the coupling degree, coordination degree, and comprehensive development value, among the subsystems. In view of the coordination of regional development under the background of high-speed railway. Zhang et al. [18] established a High-speed railway-PopulationEconomy coupling coordination degree evaluation index system to measure the coupling coordination degree of 27 provinces across the country, and analyzed the spatial connections among them.

From the above literature review, the following poins can be seen. To sum up, the following poins can be seen. For the research object, the collection and distribution technology is widely used in the port and multimodal transportation. However, in the railway freight transportation, this research has a limitation on the single line or a single transportation organization mode. For freight flow scheduling, realizing the dynamic real-time control of train flow is an imperative measure for railway transportation enterprises; for the research method, the Entropy-TOPSIS model which method can objectively evaluate the target system, is often adopted in the railway field, while the coupling development degree model, though it has been fully utilized in the economic and system science field, is rarely applied in the railway field. Hence, the combination of the Entropy-TOPSIS modle and coupling development degree model into the integrated development of the collection and distribution system will generate some new discoveries.

\section{Synergy Connotation and Characteristics of Integrated Railway Freight Collection and Distribution}

3.1. The Main Connotation of the Integrated Railway Collection and Distribution Transportation System. As a system platform, the railway collection and distribution system connects the railway loading station, road trunk and branch line, hub and technical operation station, and unloading station, realizes the balanced transportation of goods between the production and consumption places.

The railway collection and distribution system is a complete integrated logistics chain, which is usually completed by the railway and other transportation modes [19]. The railway collection and distribution system is mainly composed of three subsystems: "collection system", "transportation system", and "digestion system". The subsystems are interrelated and restricted with each other and together form a "link" for the flow of goods, cargoes and trains [19]. The flow diagram of the railway collection and distribution system is shown in Figure 1.

\subsection{Synergy Connotation and Characteristics of the Integra-} tion of Railway Freight Collection and Distribution. Synergys is a theory founded established by the German physicist Haken in the 1970s to study how the various subsystems in a complex and complex system work together well. It is an important branch of the system science.

The connotation of the integrated integration of railway freight collection and distribution is: under the condition of a certain level of transportation organization, through the close cooperation between various units and departments within the railway enterprise and the cooperation of the "Consolidation-Dispersion" side, coordinate and, complement each other's functions, and realize the capabilities of the "aggregation," "dispersion," and "transportation" subsystems are coordinated to achieve the overall optimum. Meanwhile, the integrationof railway freight collection and distribution can actively carry out collaborative marketing, expand the transportation market share, and achieve the goal of unblocked transportation and maximum benefits.

3.3. Evaluation Index System. Based on the operation process of the railway freight collection and distribution system, we combine with the components of the collection and distribution system. Then, from the perspective of the three subsystems of consolidation, transportation, and dispersion system, we analyze, the railway freight collection and distribution system coordination evaluation index system, which is shown in Figure 2. 


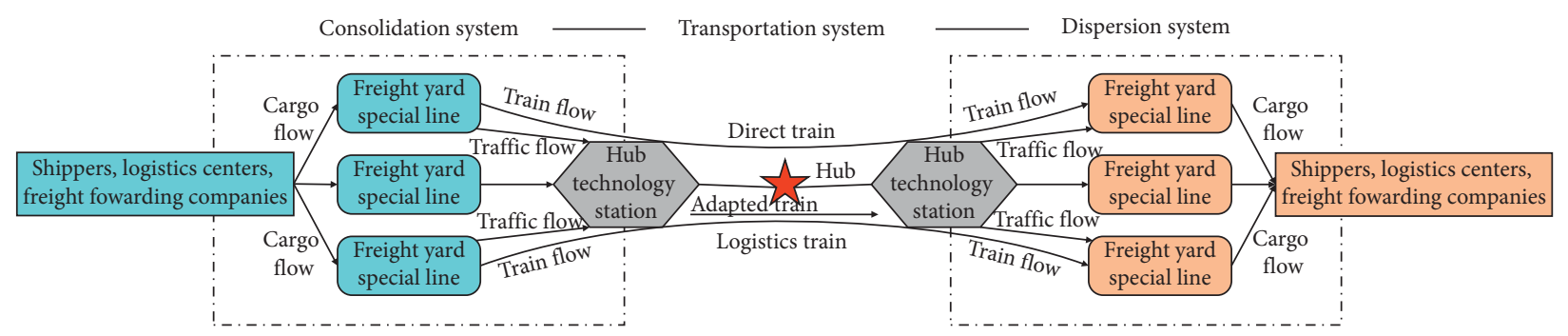

FIGURE 1: Schematic diagram of the railway collection and distribution system.

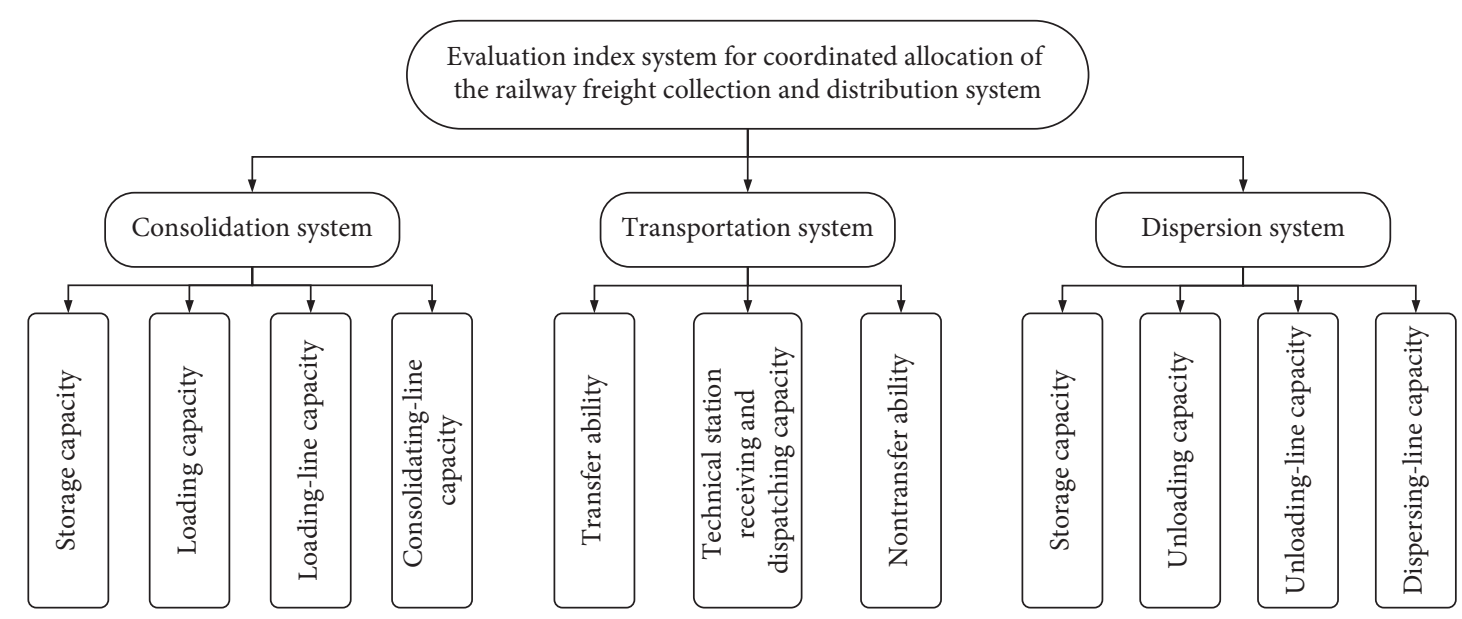

Figure 2: Evaluation index system for coordinated allocation of the railway freight collection and distribution system.

\section{Entropy-TOPSIS Coupling-Coordinated Development Degree Model}

This section introduces an "Entropy-TOPSIS couplingcoordinated development degree model" that the Entropy -weighted TOPSIS model and the coupling development degree model to quantify the synergy of the collection and distribution system. The proposed model can adapt to the real-time dynamic change of the railway network and realize the dynamic control of the collaborative configuration of the collection and distribution system. Simultaneously, for the ambiguity of the coordination size limit between the subsystems of the railway freight collection and distribution, we introduce the machine learning Fuzzy c-means (FCM) algorithm to clarify the intimacy and sparse relationship between the sub-samples, so as to divide the coordination size.

4.1. Entropy-TOPSIS Model. The Entropy-TOPSIS model [20] is an objective comprehensive evaluation method based on the finite unit multi-objective decision analysis in system engineering by combining the Entropy weight method with the TOPSIS model. The relative proximity, whichis obtained through calculation, reflects the overall situation of the coordinated development of the transportation system.

\subsubsection{Entropy Weight Method to Determine Evaluation Index Weight}

(1) Data Standardization. The data of each indicator are standardized. The indicators are generally divided into economic indicators and cost indicators.

For economic indicators,

$$
y_{i j}=\frac{x_{i j}-x_{j \min }}{x_{j \max }-x_{j \min }} .
$$

For cost indicators,

$$
y_{i j}=\frac{x_{j \max }-x_{i j}}{x_{j \max }-x_{j \min }},
$$

where $y_{i j}$ is the $j$ index value of the $i$ unit after dimensionless processing; $x_{i j}$ is the original $j$ index data of the $i$ unit.

(2) Calculation of the Information Entropy of Each Evaluation Index 


$$
\begin{aligned}
Y_{i j} & =\frac{y_{i j}}{\sum_{i=1}^{m} y_{i j}}, \\
Y & =\left(Y_{i j}\right)_{m \times n}=\left[\begin{array}{ccc}
Y_{11} & \cdots & Y_{1 n} \\
\vdots & \ddots & \vdots \\
Y_{m 1} & \cdots & Y_{m n}
\end{array}\right], \\
e_{j} & =-\frac{1}{\ln m} \sum_{i=1}^{m} Y_{i j} \ln \quad Y_{i j}, \quad j=1, \ldots, n .
\end{aligned}
$$

where $Y_{i j}$ is the $j$ index value of the $i$ unit after normalization processing, $e_{j}$ is the information entropy value of the $j$ index, $e_{j}$ is not greater than 1 , and $\ln m$ must be greater than 0 .

(3) Calculation of the Weight of Each Evaluation Index

$$
\begin{aligned}
& W_{j}=\frac{d_{j}}{\sum_{j=1}^{n} d_{j}}, \\
& d_{j}=1-e_{j} .
\end{aligned}
$$

where $W_{j}$ is the weight of the $j$ evaluation index; $d_{j}$ is the information utility value. The smaller the entropy value $e_{j}$ of the index, the larger the weight, which indicates that corresponding indicator carries more information in the integrated development of railway freight collection and distribution; otherwise, the less .

4.1.2. TOPSIS Evaluation Method to Determine Relative Proximity. The core of the TOPSIS evaluation method is to find the "relative proximity of the ideal point," that is, to obtain the relative proximity between each evaluation object and the optimal solution, which is as a basis for evaluating the pros and cons.

\section{(1) Establishing a Standardized Decision Matrix}

$$
r_{i j}=\frac{x_{i j}}{\sqrt{\sum_{j=1}^{m} x_{i j}^{2}}}, \quad 1 \leq i \leq m, 1 \leq j \leq n,
$$

where $x_{i j}$ is the $j$ index value of the $i$ unit; $r_{i j}$ is the $j$ index value of the $i$ unit after the normalization process. Since the entropy weight method has obtained the normalized matrix, which is $Y_{i j}$, this step will not be repeated.

(2) Calculation of the Weighted Standardized Decision Matrix

$$
V=\left[W_{j} Y_{i j}\right]_{m \times n}
$$

(3) Determining Positive and Negative Ideal Solutions

$$
\begin{aligned}
& A^{+}=\left\{v_{1}^{+}, \ldots, v_{n}^{+}\right\}, \\
& A^{-}=\left\{v_{1}^{-}, \ldots, v_{n}^{-}\right\} .
\end{aligned}
$$

For economic indicators:

$$
\begin{aligned}
v_{j}^{+} & =\max \left\{v_{i j}, i=1, \ldots, m\right\}, \\
v_{j}^{-} & =\min \left\{v_{i j}, i=1, \ldots, m\right\} .
\end{aligned}
$$

For cost indicators:

$$
\begin{aligned}
& v_{j}^{+}=\min \left\{v_{i j}, i=1, \ldots, m\right\}, \\
& v_{j}^{-}=\max \left\{v_{i j}, i=1, \ldots, m\right\},
\end{aligned}
$$

where $A^{+}$is the positive ideal solution; $A^{-}$is the negative ideal solution.

(4) Calculation of the Distance from Each Unit to the Positive and Negative Ideal Solutions

$$
\begin{aligned}
& D_{i}^{+}=\sqrt{\sum_{j=1}^{n}\left(v_{i j}-v_{j}^{+}\right)^{2}}, \quad i=1, \ldots, m, \\
& D_{i}^{-}=\sqrt{\sum_{j=1}^{n}\left(v_{i j}-v_{j}^{-}\right)^{2},} \quad i=1, \ldots, m,
\end{aligned}
$$

where $D_{i}^{+}$is the distance from unit $i$ to the positive ideal solution; $D_{i}^{-}$is the distance from unit $i$ to the negative ideal solution.

(5) Calculation of the Relative Proximity of Each Unit to the Optimal Plan

$$
O_{i}=\frac{\sqrt{\sum_{j=1}^{n}\left(v_{i j}-v_{j}^{-}\right)^{2}}}{\sqrt{\sum_{j=1}^{n}\left(v_{i j}-v_{j}^{+}\right)^{2}}+\sqrt{\sum_{j=1}^{n}\left(v_{i j}-v_{j}^{-}\right)^{2}}}, \quad i=1,2, \ldots, m,
$$

where $O_{i}$ is the relative proximity. It takes a value between 0 and 1 . The closer the $O_{i}$ is to 1 , the closer the evaluation object is to the optimal level; otherwise, the closer it is to 0 , the closer the evaluation object is to the worst level. This paper uses relative proximity to express the comprehensive coordination of the system.

\subsection{Coupling Development Degree Model}

4.2.1. Coupling Degree. System coupling is used to indicate an interaction relationship between multiple systems (the number of systems $\geq 2$ ). The coupling degree is used to characterize the degree of influence between subsystems. It is quantified by using the dispersion coefficient $C_{v}$ in mathematics.

According to the definition of coordination degree, this paper constructs the comprehensive benefit function of the "collection and distribution" system : 


$$
\begin{aligned}
& X=f(x)=\sum_{j_{1}}^{n_{1}} W_{j}^{1} Y_{i j}^{1}, \\
& Y=g(y)=\sum_{j_{2}}^{n_{2}} W_{j}^{2} Y_{i j}^{2}, \\
& Z=h(z)=\sum_{j_{3}}^{n_{3}} W_{j}^{3} Y_{i j}^{3},
\end{aligned}
$$

$f(x), g(y)$, and $h(z)$ are the comprehensive benefit functions of the "consolidation," "transportation," and "dispersion" systems. The weight of each system index is obtained by formula (4).

As far as the binary system is concerned, taking the "consolidation system" and "transportation system" as examples, we hope that the smaller the deviation between $f(x)$ and $g(y)$, the better. That is,

$$
C_{v}=\frac{S}{[f(x)+g(y)] / 2}=\sqrt{2\left\{1-\frac{f(x) \cdot g(y)}{[(f(x)+g(y)) / 2]^{2}}\right\}} .
$$

The smaller, the better ( $S$ is the standard deviation). As can be seen from the abovementioned formula, the necessary and sufficient conditions for making $C_{v}$ smaller are better:

$$
C=\frac{f(x) \cdot g(y)}{[(f(x)+g(y)) / 2]^{2}} \text {. }
$$

The bigger, the better. We call the formula derived above as the "coupling coordinated degree model." In the formula, $C$ is called "coupling degree of collection and distribution subsystems" (also called coordination coefficient), which reflects the quantity and degree of combination and coordination between two subsystems.

4.2.2. Coupling Development Degree. Coupling degree, which is a quantitative index to measure the excellent degree of coordination between systems or elements, can be used to measure the degree of harmony and consistency among the systems or inner-elements during the development process. However, for different collection and distribution systems under the same index system, there may be situations in which the degree of coupling and coordination among subsystems or elements is extremely similar, but the actual coordination is not consistent. Hence, the coupling coordinated degree cannot fully and systematically describe the level of coordinated development between systems, leading to the loss of accuracy of the evaluation results. In this regard, in view of the connotation of coordinated development, based on the "Environment and Economic Coupling Development Degree Model" constructed by Liao [21] scholar, we construct a "Coupling Development Degree Model of railway freight collection and distribution" based on the content of this paper.

For the binary system, the "second-degree coupling" model (taking the "Consolidation-Transportation" system as an example) is built:

$$
\begin{aligned}
& D_{(2)}=\sqrt{C_{(2)} \cdot T_{(2)}}, \\
& C_{(2)}=\frac{\sum_{j_{1}}^{n_{1}} W_{j}^{1} Y_{i j}^{1} * \sum_{j_{2}}^{n_{2}} W_{j}^{2} Y_{i j}^{2}}{\left(\left(\sum_{j_{1}}^{n_{1}} W_{j}^{1} Y_{i j}^{1}+\sum_{j_{2}}^{n_{2}} W_{j}^{2} Y_{i j}^{2}\right) / 2\right)^{2}}, \\
& T_{(2)}=\alpha * \sum_{j_{1}}^{n_{1}} W_{j}^{1} Y_{i j}^{1}+\beta * \sum_{j_{2}}^{n_{2}} W_{j}^{2} Y_{i j}^{2},
\end{aligned}
$$

where $D_{(2)}$ is the coupling development degree, $C_{(2)}$ is the coupling degree of the binary systems, and $T_{(2)}$ is the overall benefit (or level) of the binary systems; $\alpha$ and $\beta$ are undetermined coefficients. We believe that the importance of each link in the railway freight collection and distribution system is consistently, so the values of $\alpha$ and $\beta$ are set to 0.5 .

For the ternary system, the "three-degree coupling" model is built:

$$
\begin{aligned}
& D_{(3)}=\sqrt{C_{(3)} \cdot T_{(3)}}, \\
& C_{(3)}=\left\{\frac{\sum_{j_{1}}^{n_{1}} W_{j}^{1} Y_{i j}^{1} * \sum_{j_{2}}^{n_{2}} W_{j}^{2} Y_{i j}^{2} * \sum_{j_{3}}^{n_{3}} W_{j}^{3} Y_{i j}^{3}}{\left[\sum_{j_{1}}^{n_{1}} W_{j}^{1} Y_{i j}^{1}+\sum_{j_{2}}^{n_{2}} W_{j}^{2} Y_{i j}^{2}+\sum_{j_{3}}^{n_{3}} W_{j}^{3} Y_{i j}^{3}\right]^{3}}\right\}^{1 / 3}, \\
& T_{(3)}=\alpha * \sum_{j_{1}}^{n_{1}} W_{j}^{1} Y_{i j}^{1}+\beta * \sum_{j_{2}}^{n_{2}} W_{j}^{2} Y_{i j}^{2}+\gamma * \sum_{j_{3}}^{n_{3}} W_{j}^{3} Y_{i j}^{3},
\end{aligned}
$$

where $D_{(3)}$ is the coupling development degree, $C_{(3)}$ is the degree of coupling and coordination of the ternary system, $T_{(3)}$ is the overall benefit of the ternary system, $\alpha, \beta$, and $\gamma$ are the undetermined coefficients of the consolidation system, transportation system, and dispersion system, respectively, and $\alpha+\beta+\gamma=1$. In this paper, the undetermined coefficients $\alpha, \beta$, and $\gamma$ are all attached with a value of $1 / 3$.

The volume of the coupling coordinated development degree directly reflects the coordinated development degree of each subsystem or element in the system. The larger the value is, the stronger the close relationship of mutual cooperation and promotion exists between each subsystem or element, which is conducive to the sustainable development of the system.

\subsection{Fuzzy Clustering FCM Algorithm}

4.3.1. Algorithm Principle. The FCM algorithm is an unsupervised fuzzy clustering method based on the optimization of the objective function in the machine learning method. We use fuzzy mathematics to quantitatively determine the fuzzy relationship between samples quantitatively.So as to cluster objectively and accurately perform clustering, and divide the data set into multiple categories or clusters.

The mathematical relationship between the input and output of the FCM algorithm is shown as follows. 
The input-Variable set is

$$
\begin{gathered}
X=\left\{x_{1}, x_{2}, \ldots, x_{n}\right\}, \quad x_{k} \in R^{P}, \\
\text { output }\left\{\begin{array}{l}
\text { Classification matrix: } U=\left(\begin{array}{ccc}
u_{11} & \cdots & u_{1 n} \\
\vdots & \ddots & \vdots \\
u_{c 1} & \cdots & u_{c n}
\end{array}\right)_{c \times n}, \\
\text { Cluster center vector collection: } V=\left\{v_{1}, v_{2}, \ldots, v_{c}\right\}, \quad v_{k} \in R^{P} .
\end{array}\right.
\end{gathered}
$$

where $p$ represents the characteristics of the input elements, $c$ is the number of clusters, and $n$ is the number of elements in the data set. The cluster center represents the representative point of each class.

For the FCM algorithm:

Objective function:

$$
J_{m}(U, V)=\sum_{i=1}^{c} \sum_{j=1}^{n} u_{i j}^{m} d_{i j}^{2} .
$$

Restrictions:

$$
\sum_{i=1}^{c} u_{i j}=1, \quad 1 \leq j \leq n
$$

where $U$ represents the original matrix, $V$ represents the cluster center, $u_{i j}$ is the degree of membership, which refers to the degree of membership of the $j$ element corresponding to the $i$ category; and $d_{i j}^{2}$ is the distance between the element $j$ and the center point $i$ under the Euclidean distance; $m$ is a parameter of the degree of fuzzification. The interpretation of the restrictions is that the values of the degree of membership of an element to all categories add up to 1 .

The mathematical relationship corresponding to the final effect to be achieved by clustering is to replace the objective function of FCM algorithm. The expression of the optimal solution is

$$
\min \left(J_{m}(U, V)\right)=\min \left(\sum_{i=1}^{c} \sum_{j=1}^{n} u_{i j}^{m} d_{i j}^{2}\right) .
$$

The Lagrangian multiplier method is used to construct function:

$$
F=\sum_{i=1}^{c} \sum_{j=1}^{n} u_{i j}^{m} d_{i j}^{2}+\sum_{j=1}^{n} \lambda_{j}\left(\sum_{i=1}^{c} u_{i j}-1\right) .
$$

By solving the objective function, the optimal solutions of $U$ and $V$ are obtained:

$$
\begin{aligned}
u_{i j} & =\left[\sum_{k=1}^{c}\left(\frac{d_{i j}}{d_{k j}}\right)^{2 /(m-1)}\right]^{-1}, \\
v_{i} & =\frac{\sum_{j=1}^{n} x_{j} u_{i j}^{m}}{\sum_{j=1}^{n} u_{i j}^{m}}
\end{aligned}
$$

In summary, the FCM algorithm requires two parameters, one is the number of clusters $c$ and the other is the parameter $m$. In general, $c$ is much smaller than the total number of cluster samples, and at the same time, $c>1$ must be guaranteed. There is an evaluation function $L(c)$ for the selection of the number of clusters $c$ :

$$
L(c)=\frac{\sum_{i=1}^{c} \sum_{j=1}^{n} u_{i j}^{m}\left\|v_{i}-\bar{x}\right\|^{2} /(c-1)}{\sum_{i=1}^{c} \sum_{j=1}^{n} u_{i j}^{m}\left\|x_{j}-v_{i}\right\|^{2} /(n-c)} .
$$

In the formula, the numerator represents the sum of the distances between classes, and the denominator represents the sum of the distances within the classes; $m$ is a parameter that controls the flexibility of the algorithm. If $m$ is too large, the clustering effect will be weak; if $m$ is too small, the algorithm will approach the hard-clustering algorithm. By referring to the common sense of multiple papers, it is more appropriate to choose $m=2.0$, which causes less noise to the data.

4.3.2. Algorithm Steps. According to the algorithm principle, the algorithm execution process is shown in Figure 3.

\section{Case Analysis}

Based on the research foundation of related projects, weselect the Tongchuan Depot of Xi'an Railway Bureau that meets the basic requirements of the gathering and transportation system as the target system to start an example analysis.

The jurisdiction of the China Railway Xi'an Group Co., Ltd Tongchuan Depot is the two branch lines of Xiantong line and Meiqi line, with an operating mileage of 177.182 kilometers. The stations pass through Gaoling County, Sanyuan County, Yanliang District of Xi'an City, Fuping County, Yaozhou District of Tongchuan City, and Tongchuan City. It has 24 stations under its jurisdiction and is mainly responsible for the transportation of coal, aluminum, coke, cement, building materials, grain, chemical fertilizer, and other materials and people's daily necessities in the Tongchuan area, along the line and in various jurisdictions. The simplified plan of the Tongchuan Depot is shown in Figure 4 .

Through the intelligent information system, the relevant guarantee information such as the capacity schedule of each loading and unloading point and the freight volume 


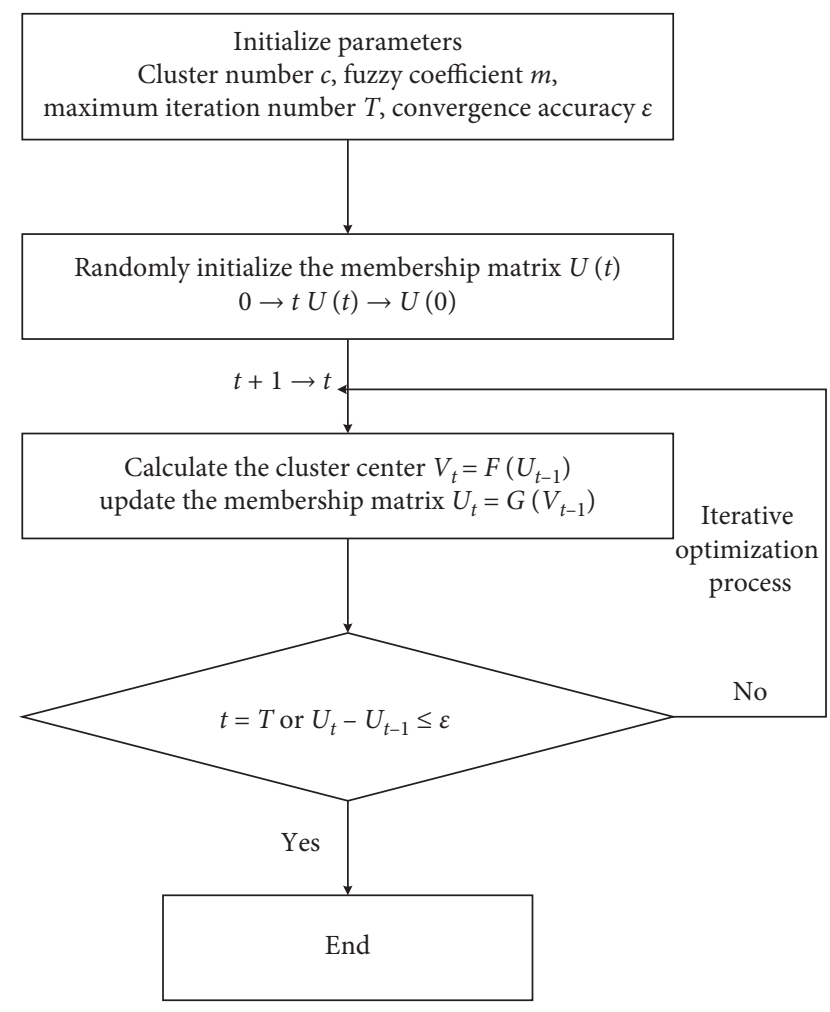

FIgURE 3: FCM algorithm flowchart.

summary report is extracted.By counting, analyzing, and filtering the information in the freight traffic report provided by the Tongchuan Depot,we select 13 stations as the target stations to build the collection and distribution system. After taking into account the expected difficulties in the subsequent indicators, we select the number of loading/unloading cargoes, the capacity of consolidating/distributing lines, the capacity of receiving/departing from technical stations, and the number of transfer or nontransfer cargoes as indicators. It should be noted that since the number of non-transfer cargoes at Meijiaping Station has decreased, the number of shunting cargoes can better represent the operating capacity of the technical station. Therefore, the analysis is mainly based on the number of shunting cargoes.

According to the selected index statistics, the initial data of the Tongchuan Train Depot collection and distribution system in 2017 is shown in Tables 1-3.

According to formula (12), the relative proximity of the system in each month of the Tongchuan Depot in 2017 is shown in Table 4.

It can be seen that in the first half of 2017, the coordination of the system fluctuates greatly, and the development is more irregular; in the second half, the coordinated transition is relatively small, and the development tends to be stable. Among them, the system in April has the highest comprehensive coordination and cooperates most closely coordinated system. This is closely related to the operation of each station every month.

In order to more intuitively reflect the closeness of the coordinated development among the various subsystems, based on the original data, according to the description in
Section 4, we construct a Multi-Entropy-TOPSIS Coupling Development Degree Mode. The obtained coupling development degree is a quantitative expression of the coordinated development relationship between the collection and distribution subsystems of the Tongchuan Depot in 2017 and can more intuitively reflect the strength of interaction and the level of coordinated development among the various subsystems. The obtained results are shown in Table 5. In order to more intuitively reflect the closeness of the coordinated development among the various subsystems, based on the original data, according to the description in Section 4, we construct a multi-Entropy-TOPSIS Coupling Development Degree Mode. The obtained coupling development degree is a quantitative expression of the coordinated development relationship between the collection and distribution subsystems of the Tongchuan Depot in 2017, and can more intuitively reflect the strength of interaction and the level of coordinated development among the various subsystems. The obtained results are shown in Table 5 .

Through the horizontal analysis of results in Table 5, the coupling development degree between the binary systems is generally higher than that of the ternary system, indicating that the coordination between the binary systems is relatively tight, but the overall coordination is loose; in the results of the binary system coupling results $D_{2}$, the "Consolidation-Dispersion" system coupling development degree is relatively low except for January and February, and the remaining months are at the highest values among other coupling methods. It shows that, among the various system coupling methods, the internal coordination between the consolidation system and dispersion system is the closest, which means that the operation efficiency of the "Consolidation-Dispersion" system is higher and the empty-weight distribution is more balanced.

Longitudinal analysis, as a whole, due to the increase in the number of passenger trains and the addition of temporary passenger trains during the Spring Festival, will relatively affect the development of freight capacity, so the coupling development degree between multiple systems is relatively low in February; from the range of the $D_{2}$, in addition to "Consolidation-Dispersion," the internal coordinated development of other multisystem combinations gradually changed from disorder to order. Among them, the value of the coupling coordination development degree in February and May is relatively low.We definethem as the bottleneck months, and the impact factors involved are defined as bottleneck factors. Through the analysis of statistical data, it can be seen that the key factor affecting the month of bottlenecks is the Meijiaping Station, which is the hub technology station of the transportation subsystem. Its receiving-dispatching capacity and transfer capacity in February and May are among the lowest and second lowest in the year 2017.

Due to the difficulty of control, it is easier to control the binary system of the collection and distribution system under the same time and space than the ternary system. Hence, in view of the more difficult direct control, we consider improving the coordination of the ternary system by improving the coordination of the binary system to improve the overall coordination of the target transportation 


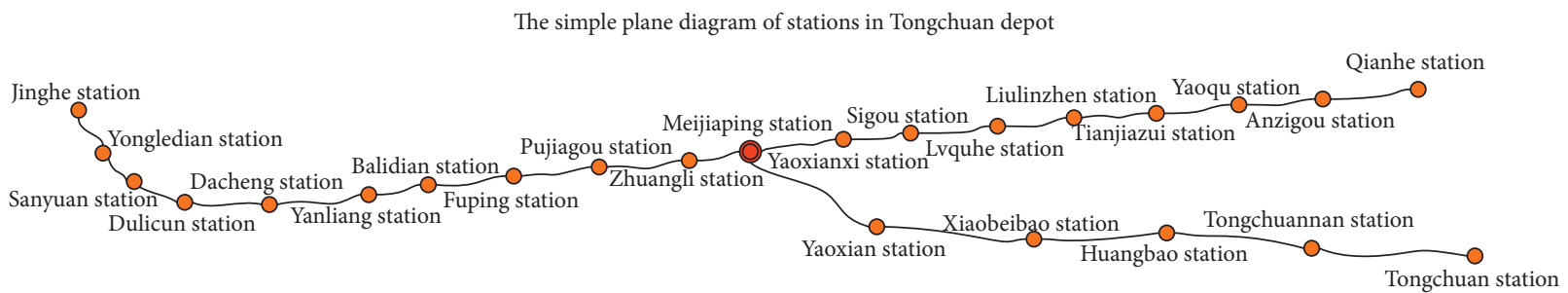

FIgURE 4: Simplified floor plan of the Tongchuan Depot.

Table 1: Initial statistics of the "consolidation" system of the Tongchuan Train Depot in each month in 2017.

\begin{tabular}{|c|c|c|c|c|c|c|c|c|c|}
\hline Month & $\begin{array}{l}\text { Qianhe } \\
\text { loading } \\
\text { capacity }\end{array}$ & $\begin{array}{l}\text { Anzigou } \\
\text { loading } \\
\text { capacity }\end{array}$ & $\begin{array}{l}\text { Yaoqu } \\
\text { loading } \\
\text { capacity }\end{array}$ & $\begin{array}{c}\text { Tianjiazui } \\
\text { loading } \\
\text { capacity }\end{array}$ & $\begin{array}{c}\text { Liulinzhen } \\
\text { loading } \\
\text { capacity }\end{array}$ & $\begin{array}{c}\text { Huangbao } \\
\text { loading } \\
\text { capacity }\end{array}$ & $\begin{array}{l}\text { Yaoxian } \\
\text { loading } \\
\text { capacity }\end{array}$ & $\begin{array}{l}\text { Consolidating- } \\
\text { line1 capacity }\end{array}$ & $\begin{array}{l}\text { Consolidating- } \\
\text { line } 2 \text { capacity }\end{array}$ \\
\hline 1 & 2979 & 1513 & 3103 & 1498 & 773 & 478 & 163 & 4121 & 634 \\
\hline 2 & 3875 & 1497 & 4467 & 1663 & 1105 & 433 & 133 & 4689 & 493 \\
\hline 3 & 3302 & 2113 & 3443 & 1942 & 1103 & 402 & 187 & 4002 & 513 \\
\hline 4 & 4327 & 1892 & 4567 & 2384 & 1002 & 663 & 87 & 4896 & 576 \\
\hline 5 & 4243 & 2189 & 4345 & 2415 & 1127 & 613 & 113 & 4890 & 553 \\
\hline 6 & 3217 & 2113 & 3254 & 2267 & 833 & 601 & 98 & 3967 & 663 \\
\hline 7 & 3174 & 1874 & 3665 & 2078 & 872 & 801 & 90 & 4323 & 830 \\
\hline 8 & 3042 & 2298 & 4334 & 2575 & 1045 & 553 & 57 & 4897 & 590 \\
\hline 9 & 3487 & 1684 & 3654 & 2288 & 788 & 153 & 32 & 4796 & 102 \\
\hline 10 & 3198 & 1937 & 3471 & 2104 & 1015 & 133 & 34 & 4834 & 297 \\
\hline 11 & 3023 & 1983 & 3112 & 1904 & 801 & 221 & 124 & 4089 & 404 \\
\hline 12 & 3144 & 1873 & 3547 & 2075 & 843 & 234 & 81 & 4822 & 334 \\
\hline
\end{tabular}

TABLe 2: Initial statistics of the "transportation" system of the Tongchuan Depot in 2017.

\begin{tabular}{lccc}
\hline Month & Meijiaping receiving capacity & Meijiaping dispatching capacity & Meijiaping transfer ability \\
\hline 1 & 29167 & 29512 & 25780 \\
2 & 21783 & 21914 & 18633 \\
3 & 28694 & 28839 & 25510 \\
4 & 26134 & 26048 & 23046 \\
5 & 21976 & 20733 & 18696 \\
6 & 24343 & 24121 & 20924 \\
7 & 26196 & 25382 & 23142 \\
8 & 23287 & 23490 & 20074 \\
9 & 25334 & 25229 & 22013 \\
10 & 27565 & 27475 & 24761 \\
11 & 27432 & 27348 & 24001 \\
12 & 28910 & 28905 & 25325 \\
\hline
\end{tabular}

TABle 3: Initial statistics of the "dispersion" system in the Tongchuan Depot in 2017.

\begin{tabular}{|c|c|c|c|c|c|c|}
\hline Month & $\begin{array}{l}\text { Fuping unloading } \\
\text { capacity }\end{array}$ & $\begin{array}{l}\text { Yanliang unloading } \\
\text { capacity }\end{array}$ & $\begin{array}{c}\text { Sanyuan unloading } \\
\text { capacity }\end{array}$ & $\begin{array}{l}\text { Yongledian unloading } \\
\text { capacity }\end{array}$ & $\begin{array}{l}\text { Jinghe unloading } \\
\text { capacity }\end{array}$ & $\begin{array}{c}\text { Dispersing- } \\
\text { line capacity }\end{array}$ \\
\hline 1 & 11 & 111 & 366 & 27 & 552 & 674 \\
\hline 2 & 12 & 39 & 221 & 18 & 421 & 784 \\
\hline 3 & 23 & 24 & 401 & 25 & 572 & 853 \\
\hline 4 & 12 & 58 & 532 & 32 & 601 & 835 \\
\hline 5 & 5 & 62 & 640 & 47 & 653 & 894 \\
\hline 6 & 16 & 94 & 620 & 102 & 731 & 889 \\
\hline 7 & 33 & 68 & 756 & 98 & 551 & 857 \\
\hline 8 & 20 & 95 & 715 & 0 & 482 & 898 \\
\hline 9 & 56 & 150 & 988 & 31 & 445 & 1134 \\
\hline 10 & 53 & 133 & 955 & 24 & 385 & 1032 \\
\hline 11 & 85 & 86 & 717 & 12 & 477 & 986 \\
\hline 12 & 95 & 63 & 555 & 27 & 455 & 779 \\
\hline
\end{tabular}


TABLE 4: The relative proximity degree of the integrated collection and distribution system of Tongchuan Railway Depot in each month in 2017.

\begin{tabular}{lcc}
\hline Month & $O_{i}$ & Sort \\
\hline 1 & 0.3021 & 12 \\
2 & 0.4470 & 4 \\
3 & 0.4077 & 7 \\
4 & 0.5674 & 1 \\
5 & 0.5517 & 2 \\
6 & 0.3900 & 10 \\
7 & 0.4237 & 5 \\
8 & 0.3733 & 11 \\
9 & 0.4203 & 6 \\
10 & 0.4045 & 8 \\
11 & 0.4014 & 9 \\
12 & 0.4592 & 3 \\
\hline
\end{tabular}

TABle 5: The results of the multiple coupling development degree $D_{i}$ of the collection and distribution system of Tongchuan Depot in 2017.

\begin{tabular}{lcccc}
\hline \multirow{2}{*}{$\begin{array}{c}\text { Bonth } \\
\text { Consolidation-transportation }\end{array}$} & $\begin{array}{c}\text { Ternary system coupling } D_{3} \\
\text { Consolidation-dispersion } \\
D_{2,1}\end{array}$ & $D_{2,2}$ & $\begin{array}{c}\text { Transportidation-dispersion } \\
\text { Consolionsportation- } \\
\text { dispersion }\end{array}$ \\
\hline 1 & 0.1417 & 0.1349 & 0.1374 & 0.0797 \\
2 & 0.0385 & 0.1192 & 0.0371 & 0.0492 \\
3 & 0.1665 & 0.1610 & 0.1369 & 0.0921 \\
4 & 0.1476 & 0.1785 & 0.1243 & 0.0951 \\
5 & 0.0230 & 0.1927 & 0.0229 & 0.0519 \\
6 & 0.1091 & 0.1887 & 0.1105 & 0.0837 \\
7 & 0.1379 & 0.1957 & 0.1355 & 0.0937 \\
8 & 0.0945 & 0.1662 & 0.0877 & 0.0753 \\
9 & 0.1226 & 0.1829 & 0.1272 & 0.0870 \\
10 & 0.1490 & 0.1815 & 0.1497 & 0.0937 \\
11 & 0.1315 & 0.1588 & 0.1489 & 0.0864 \\
Average $\bar{D}_{i}$ & 0.1546 & 0.1807 & 0.1592 & 0.0960 \\
\hline
\end{tabular}

TABLE 6: Correlation coefficients between multiple systems.

\begin{tabular}{lc}
\hline Characteristic & Correlation coefficients \\
\hline$D_{3}$ 与 $D_{2,1}$ & 0.953 \\
$D_{3}$ 与 $D_{2,1}$ & 0.422 \\
$D_{3}$ 与 $D_{2,1}$ & 0.939 \\
\hline
\end{tabular}

system. Using the Correl function, according to the data in Table 5, we calculate the correlation coefficient of the coupling coordination development degree of each multielement system. The calculation results are shown in Table 6.

The results show that the coordinated development of the ternary system is not closely related to the "Consolidation-Dispersion" of the binary system, but highly related to the "Consolidation-Transportation" and "Transportation-Dispersion." Therefore, if we want to improve the overall coordination of the constructed Tongchuan Depot collection and distribution system, the focus of the coordination configuration should be on strengthening the "Consolidation-Transportation" and "Transportation-Dispersion" of these two types of binary systems.

Combined with the above mentioned analysis, the bottleneck factors affecting the coordinated development of
TABLE 7: The relative proximity degree of the integrated collection and distribution system of Tongchuan Railway Depot in each month in 2018.

\begin{tabular}{lcc}
\hline Month & $O_{i}$ & Sort \\
\hline 1 & 0.5257 & 1 \\
2 & 0.3615 & 12 \\
3 & 0.4909 & 3 \\
4 & 0.4252 & 7 \\
5 & 0.4276 & 6 \\
6 & 0.4645 & 4 \\
7 & 0.5164 & 2 \\
8 & 0.3766 & 11 \\
9 & 0.3788 & 10 \\
10 & 0.4473 & 5 \\
11 & 0.3956 & 9 \\
12 & 0.4133 & 8 \\
\hline
\end{tabular}

Tongchuan Train Depot collection and distribution system and the correlation between multiple systems are analyzed. In order to meet the requirements of improving the volume of railway freight and the comprehensive utilization efficiency of the railway networks, this paper mainly focuses on 
the following three aspects to strengthen the overall internal coordinated development of the collection and distribution system: the operation efficiency of the freight yard station, the traffic organization of the hub marshalling station and the technical standard of the station line to organize and control the coordinated configuration of the system in the 2017 bottleneck month of the Tongchuan Depot.

\subsection{The Operation Efficiency of the Freight Yards and Stations.} According to the results of the horizontal analysis of the coupling development degree, the system stations in January and February still need to strengthen the coordination ability of collecting and distributing operations. The operation efficiency of the freight collection and distribution terminal is mainly affected by the fluctuation of the transportation cargo flow, the fluctuation of the operation time, the unsmooth operation connection, the mutual interference and the interference of the adjacent subsystems. In view of the current freight environment of the Tongchuan Depot, it is recommended to make full use of the effective cargo space in the freight yard under its jurisdiction and strengthen the coordination of freight flow distribution. The number of cargos in the freight yard can not only directly affect the storage capacity of the yard, but also indirectly affect the loading and unloading capacity of the yard. According to "The table statistics of the capacity of each loading and unloading point in the Tongchuan Depot," it can be considered that the Qianhezhen station, Anzigou station, Tianjiazui station and Liulinzhen station, all of which have less effective storage space, should adopt an effective storage space sharing strategy and strengthen the coordination of the distribution of empty and heavy cargoes flow among the freight yards. Secondly, to improve the collection and distribution efficiency, we consider strengthening the coordination efficiency of the internal operations of the coordinated collection and distribution yard, which can shorten the connection time.

\subsection{Organization of Traffic Flow at a Hub Marshalling} Station. According to the longitudinal analysis results of the coupling development degree, Meijiaping Station, which is the key marshalling station that affects the coordinated development of the entire "ConsolidationTransportation-Dispersion." The poor organization of the operation coordination in the station directly causes the transit time of the cargoes and the residence time of the operation. The increase of negative feedback will affect the coordinated development of the whole railway system. For the inside of the yard, when the traffic flow arrives in a certain period of time or a direction, the yard should communicate with the dispatcher of the dispatching station to give priority access to the required traffic flow or nonadjustable transfer train. For urgent cargoes at the destination freight yard, the following principles should be adopted for coordination: "delivery first, picking up first; disassembling cares for delivery; delivery cares for loading and unloading; loading and unloading cares for picking up; and picking up cares for marshling”.

5.3. The Technical Standards of Station Lines. At present, domestic freight stations are gradually fully electrified with single and double lines, but most of the freight yards in the Tongchuan Depot, such as Zhuangli Station, Yongledian Station and Yaoxian Station, still maintain manual loading and unloading, which will directly affect the operation efficiency and safety. In addition, as the modernization of railway logistics advances, it is necessary for the stations to upgrade the technical standards of the lines. It is possible to adopt reasonable configuration and transformation of the rain shed (quantity, construction and use area), platform, open cargo area, and special lines of some low-level technical freight yards in the Tongchuan Depot. By comparing the efficiency, capacity, price, technical parameters and other factors of facilities, we determine the facilities and equipment that should be configured in the freight yard, monitor the whole life cycle of facilities and equipment to realize dynamic facility equipment configuration and control the cost and improve the input-output ratio of the system.

Based on the abovementioned analysis, the bottleneck problems and rectification plans of the system are fed back to the Tongchuan Depot. After a year of follow-up statistics, atthe end of 2018, the initial statistics of the collection and transportation system of the Tongchuan Depot under the same indicators were compiled. According to formula (12), the relative proximity of the integrated system of gathering and transportation in the Tongchuan Depot in 2018 is shown in Table 7.

Compared with the data in Table 4,it can be shown in Figure 5 that the overall coordination of the Tongchuan Depot collection and distribution system in 2018 has less fluctuations and a relatively smooth development compared with the 2017. It shows that after organizational adjustment, the overall development trend of coordination in each month of 2018 is relatively consistent and the overall development is relatively balanced.

In the same way, a multi-system Entropy-TOPSIS Coupling Development Degree Model is constructed to quantify the coordinated development of the collection and distribution subsystems of the Tongchuan Depot in 2018. The value of coupling coordination development degree is obtained as shown in Table 8.

The purpose of the paper is to analyze whether the synergy among the ternary subsystems of the Tongchuan Depot has been improved. However, as synergy is a fuzzy concept, the coupling development degree should be a quantified embodiment of the synergy. Therefore, we use FCM algorithm to divide the value of the coupling development degree to compare and analyze whether the coordination has been improved. For $D_{3}$ in 2017, first the number of clusters $c$ by formula (24) is selected, and then it is determined that 4 is the optimal number of clusters for fuzzy clustering. The final clustering result is $[(2,5),(1,8),(6,9,11),(3,4,7,10,12)]$ 


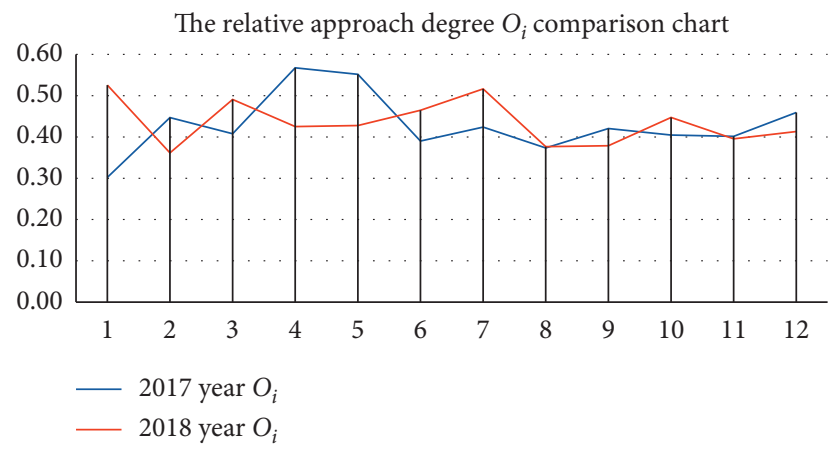

Figure 5: Comparison of relative proximity degree.

TABLE 8: The results of the multiple coupling coordinated development degree $D_{i}$ of the collection and distribution system of Tongchuan Depot in 2018.

\begin{tabular}{|c|c|c|c|c|}
\hline \multirow[b]{2}{*}{ Month } & \multicolumn{2}{|c|}{ Binary system coupling $D_{2}$} & \multicolumn{2}{|c|}{ Ternary system coupling $D_{3}$} \\
\hline & $\begin{array}{l}\text { Consolidation- } \\
\text { transportation } D_{2,1}\end{array}$ & $\begin{array}{l}\text { Consolidation-dispersion } \\
\qquad D_{2,2}\end{array}$ & $\begin{array}{l}\text { Transportation-dispersion } \\
\qquad D_{2,3}\end{array}$ & Consolidation-transportationdispersion \\
\hline 1 & 0.1721 & 0.1828 & 0.1563 & 0.0997 \\
\hline 2 & 0.0405 & 0.1645 & 0.0401 & 0.0541 \\
\hline 3 & 0.1717 & 0.1712 & 0.1436 & 0.0965 \\
\hline 4 & 0.1407 & 0.1906 & 0.1376 & 0.0931 \\
\hline 5 & 0.0499 & 0.1935 & 0.0495 & 0.0647 \\
\hline 6 & 0.1100 & 0.1901 & 0.1139 & 0.0852 \\
\hline 7 & 0.1527 & 0.2042 & 0.1500 & 0.1004 \\
\hline 8 & 0.0990 & 0.1811 & 0.0970 & 0.0782 \\
\hline 9 & 0.1262 & 0.1779 & 0.1274 & 0.0859 \\
\hline 10 & 0.1600 & 0.1949 & 0.1507 & 0.0996 \\
\hline 11 & 0.1469 & 0.1726 & 0.1455 & 0.0905 \\
\hline 12 & 0.1598 & 0.1746 & 0.1549 & 0.0947 \\
\hline Average $\bar{D}_{i}$ & 0.1275 & 0.1832 & 0.1222 & 0.0869 \\
\hline
\end{tabular}

TABLE 9: Levels of the coupling development degree of the ternary system in each month of 2017.

\begin{tabular}{lc}
\hline Month & Coupling development level \\
\hline February and May & Primary coordinated development \\
January and August & Intermediate coordinated development \\
June, September, and November & Good coordinated development \\
March, April, July, October, and December & Quality coordinated development \\
\hline
\end{tabular}

(statistics by month). The classification results of the coupling development degree is shown in Table 9.

By using the level division in Table 9 as a reference, and by adopting the same calculation method in the above formula (24), we can determine that 3 is the optimal number of clusters for fuzzy clustering of $D_{3}$ in 2018, and the clustering result is $[(2,5),(4,6,8,9,11),(1,3,7,10$, 12)]. According to the classification of the coupling coordination level of the ternary system in each month of 2017 , it can be seen that the value of the coupling development degree in each month of 2018 is higher than the highest value in the primary coordination development category, indicating thatthrough the improvement of the bottleneck factors, the overall internal coordination of the system in 2018 is above the primary coordination; that is, the coordination of the collection and distribution system has been improved.

In order to more intuitively reflect the coordinated floating changes between the multi-systems, the annual averages of the coordinated development degree of the binary and ternary systems are compared. The result is shown in Figure 6.

To sum up, through the analysis and improvement of the bottleneck factors that affect the coordinated development of the collection and distribution system, the following results can be found: for the overall development of the system, the system in 2018 is generally smooth and the synergy effect is better; for the internal coordination relationship of the system, from the comparison results of the coupling development degree, it can be seen that the coupling 


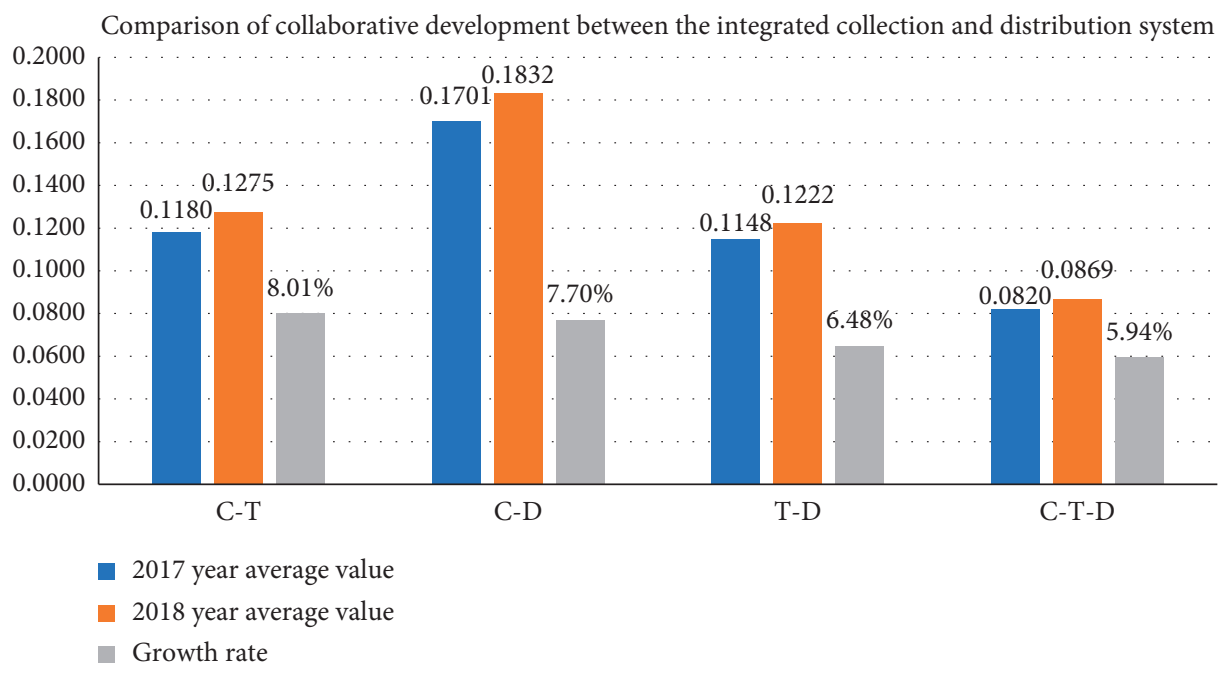

Figure 6: Comparison of the collaborative development between the integrated collection and distribution system.

coordination development degree between various multisystems has improved compared with 2017. Furthermore, with the improvement of the capacity between the two types of binary systems of "Consolidation-Dispersion" and "Transportation-Dispersion," the integration and coordination between the "Consolidation-Transportation-Dispersion" ternary subsystems of the Tongchuan Depot increased by $5.94 \%$.

\section{Conclusions}

Based on the integration of collection and distribution theory, synergy theory, coupling theory, and fuzzy mathematics, this paper constructs the "Entropy-TOPSIS Coupling Development Degree Model" for quantitative analysis of the synergy between collection and distribution systems, which provides a new method for the research on the coordinated development of an integrated railway freight collection and distribution system. Compared with the expert scoring method and the AHP method, the EntropyTOPSIS can help reduce the randomness and uncertainty of the overall collaborative evaluation of the system, and makes the evaluation method more reliable; the coupling development degree model can describe the internal coordinated development relationship of various aspects in detail, and the quantitative analysis effect is effective. The method simultaneously incorporates the ideas of fuzzy mathematics in machine learning, which has has better robustness to the random freight flows. Through the quantitative analysis of the coordination of the Tongchuan Depot System of the China Railway Xi' an Group Co., Ltd. The bottleneck factors that affect the synergy development of the system are identified, and the rectification programs are proposed. Through one-year follow-up research, the results show that in 2018, the synergy of the Tongchuan Depot integrated transportation system in 2018 increased by $5.94 \%$ compared with that in 2017 . The results verify the practicality of the intelligent analysis model. However, for the weight of the model's comprehensive benefit function, a part of the coupling development degree model in this paper, the current research assumes that the importance of each subsystem is the same, but in the actual transportation organization, the phenomenon of uneven resource allocation will inevitably occur. The importance of each system can be considered in subsequent studies, which will enrich the integrated research system of the railway freight collection and distribution. In addition, the analysis time will be refined, from month to week, so as to improve the effect of collaborative analysis.

\section{Data Availability}

The data used to support the findings of this study are available from the corresponding author upon request.

\section{Conflicts of Interest}

The authors declare that there are no conflicts of interest regarding the publication of this paper.

\section{Acknowledgments}

This study was supported by the National Key R\&D Program of China (2018YFB1201401) and the Fundamental Research Funds for the Central Universities (2019JBM030).

\section{References}

[1] E. Alan, Elements of Shipping, Chapman \& Hall, London, UK, 1989.

[2] K. J. Button, Transport Econmics, Edward Alger Publishing Ltd., Cheltenham, UK, 2nd edition, 1990.

[3] F. Huang, Coordination and Optimization of Port Logistics System Collecting and Dispatching Links, Southwest Jiaotong University, Chengdu, China, 2006.

[4] Y. B. Geng, "Development of port collection and distribution railway under the strategy of transportation structure adjustment," Port Science \& Technology, vol. 12, pp. 2-5, 2019. 
[5] W. Xu, "Research on the construction scheme of special railway line for collection and distribution in Tonghai port," Value Engineering, vol. 14, pp. 176-179, 2020.

[6] L. Y. Wu, Research on the Coordination Evaluation of the Railway Transportation System in Caofeidian Port Area, Beijing Jiaotong University, Beijing, China, 2018.

[7] L. Kong and P. He, "Research on the capacity coordination of Shenhua heavy-duty coal transportation line gathering and transportation system," Railway Transportation and Economy, vol. 39, no. 13, pp. 57-62, 2018.

[8] F. L. Fang, Z. Y. Chen, and Z. P. Lei, "Motivation and practice of synergetics for the integration of railway heavy-duty transportation collection and distribution," Railway Transport and Economy, vol. 8, pp. 25-29, 2018.

[9] X. H. Yu, "Analysis of cooperative technology of gathering and distributing system of heavy haul railway," Plant Maintenance Engineering, vol. 10, pp. 152-153, 2019.

[10] D. Liang and B. L. Lin, "Research on the strategic optimization model of railway transportation dynamic train flow organization," Systems Engineering-Theory \& Practice, vol. 1, pp. 77-84, 2007.

[11] L. Wang, B. L. Lin, J. J. Ma, and K. Y. Wen, "Methods for calculating dynamic traffic flow and optimizing transport resource allocation for bottleneck section of railway network," China Railway Science, vol. 3, pp. 116-123, 2016.

[12] F. Xue, L. Zhao, and Q. L. Fan, "Research on coupling and adjustment of stage plan and dynamic car flow in marshalling station," Journal of the China Railway Society, vol. 1, no. 2, pp. 18-26, 2020.

[13] R. Varadarajan, "Symbiotic marketing revisited," Journal of Marketing, vol. 50, no. 1, pp. 1473-1481, 1986.

[14] H. Xie, "Analysis on the selection of collaborative marketing objects," Modern Business Trade Industry, vol. 22, no. 5, p. 121, 2020.

[15] Y. L. Sun, Research on Partner Evaluation in the Construction of Logistics Supply and Demand Alliance, Northeastern University, Boston, MA, USA, 2006.

[16] X. N. Yin and X. Z. Bao, "Financial risk assessment of emerging enterprises based on entropy weight TOPSIS method-taking biopharmaceutical industry as an example," Friends of Accounting, vol. 4, pp. 70-74, 2017.

[17] Q. Wang and F. H. Tang, "Time and space differentiation of the coordinated development of ecological-economic-social system coupling in Dongting Lake area," Economic Geography, vol. 12, pp. 161-167+202, 2015.

[18] Q. L. Zhang, G. Cheng, and J. Yang, "Research on the spatial connection of high-speed rail-population-economic coupling and coordination," Science of Surveying and Mapping, vol. 7, pp. 190-198, 2020.

[19] H. K. Zhao, T. Wang, K. Song, and Y. S. Hu, "Research on the coordinated development of railway freight transportation system," China Railways, vol. 10, pp. 1-6, 2014.

[20] W. C. Li, Z. X. Wang, and Q. X. Cui, "Design of multi-attribute group decision making based on five kinds of intuitionistic fuzzy numbers TOPSIS," Statistics \& Decision, vol. 8, pp. 41-45, 2017.

[21] C. B. Liao, "QuantitativeEvaluation and classification system of coordinated development of environment and economy-taking the pearl river delta urban agglomeration as an example," Tropical Geography, vol. 19, no. 2, pp. 76-82, 1999. 